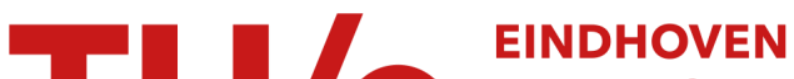 UNIVERSITY OF TECHNOLOGY
}

\section{Modeling in cardiopulmonary resuscitation : pumping the heart}

Citation for published version (APA):

Noordergraaf, G. J., Dijkema, T. J., Kortsmit, W. J. P. M., Schilders, W. H. A., Scheffer, G. J., \& Noordergraaf, A. (2006). Modeling in cardiopulmonary resuscitation : pumping the heart. (CASA-report; Vol. 0609). Technische Universiteit Eindhoven.

Document status and date:

Published: 01/01/2006

\section{Document Version:}

Publisher's PDF, also known as Version of Record (includes final page, issue and volume numbers)

\section{Please check the document version of this publication:}

- A submitted manuscript is the version of the article upon submission and before peer-review. There can be important differences between the submitted version and the official published version of record. People interested in the research are advised to contact the author for the final version of the publication, or visit the $\mathrm{DOI}$ to the publisher's website.

- The final author version and the galley proof are versions of the publication after peer review.

- The final published version features the final layout of the paper including the volume, issue and page numbers.

Link to publication

\section{General rights}

Copyright and moral rights for the publications made accessible in the public portal are retained by the authors and/or other copyright owners and it is a condition of accessing publications that users recognise and abide by the legal requirements associated with these rights.

- Users may download and print one copy of any publication from the public portal for the purpose of private study or research.

- You may not further distribute the material or use it for any profit-making activity or commercial gain

- You may freely distribute the URL identifying the publication in the public portal.

If the publication is distributed under the terms of Article 25fa of the Dutch Copyright Act, indicated by the "Taverne" license above, please follow below link for the End User Agreement:

www.tue.nl/taverne

Take down policy

If you believe that this document breaches copyright please contact us at:

openaccess@tue.nl

providing details and we will investigate your claim. 


\title{
Modeling in Cardiopulmonary Resuscitation: Pumping the Heart
}

\author{
GERRIT J. NOORDERGRAAF, ${ }^{* * * *}$ TAMMO J. DIJKEMA, ${ }^{\dagger}$ WIL J.P.M. KORTSMIT, ${ }^{\ddagger}$ WIL H.A. SCHILDERS, ${ }^{\ddagger}$ \\ GERT J. SCHEFFER, ${ }^{\S}$ and ABRAHAM NOORDERGRAAF ${ }^{\mathbb{}}$
}

\begin{abstract}
Physiology offers insights into fundamental aspects of the circulation, even when the circulation is nonphysiological, as during cardiac arrest and cardiopulmonary resuscitation (CPR). Human and animal experiments offer only limited insights as they are susceptible to uncontrollable variables. Mathematical models offer quantitative results for flows, pressures and volumes under clearly defined conditions, chosen by the experimenters. This report describes the left ventricle and its immediate environment as the core of a larger mathematical model. The model works normally under physiological conditions, and is specifically designed to allow understanding of flow, pressure, and volume phenomena under CPR as an extreme pathophysiological scenario. Using impedance-defined flow, the importance of valves for both the contracting as well as the asystolic ventricle is quantified. It demonstrates the role of venous pressure, sloshing of blood and flow around the cardiovascular circuit. The flow of $8 \mathrm{~mL} / \mathrm{s}$, in a pathological situation is demonstrated to be due not to cardiac compression, but to venous pressure. The principal conclusions are that the model functions in the physiological situation and that in an asystolic left ventricle with competent valves, intrathoracic pressure can modestly replace contractile properties. In an asystolic ventricle without competent valves, intrathoracic pressure
\end{abstract}

\footnotetext{
*Department of Anesthesia and Resuscitation, St. Elisabeth Hospital Tilburg, Tilburg, The Netherlands.

${ }^{\dagger}$ Department of Mathematics and Computer Science, Utrecht University, Utrecht, The Netherlands.

${ }_{\ddagger}$ Department of Mathematics and Computer Science, Eindhoven University of Technology, Eindhoven, The Netherlands.

${ }^{\S}$ Department of Anesthesiology, University Medical Center Nijmegen, Nijmegen, The Netherlands.

TCardiovascular Studies Unit, University of Pennsylvania, Philadelphia, Pennsylvania.

**To whom correspondence should be addressed at Department of Anesthesia and Resuscitation, St. Elisabeth Hospital Tilburg, Hilvarenbeekseweg 60, 5022 GC Tilburg, The Netherlands. E-mail: gj.noordergraaf@wxs.nl
}

variations accomplish little. The cardiac pump theory in CPR has limited applicability.

Key words: cardiopulmonary resuscitation (CPR); circulation; modeling; pathophysiology; physiology.

\section{INTRODUCTION}

The application of external cardiopulmonary resuscitation (CPR), as suggested by Kouwenhoven et al. (1960), has for the most part remained unchanged, despite an impressive array of investigations in animals and in humans. The transition from the invasive technique of open chest cardiac resuscitation (OCCR) to closed chest cardiac resuscitation (CCCR), a noninvasive technique, coincided with a seemingly significant downturn in the survival rate. This raised a warning sign for other investigators with respect to Kouwenhoven's assumption that CCCR was a straight imitation of OCCR (Weiser et al., 1962). The steadfast nature of the CCCR technique has, for the most part, been caused by difficulty in achieving reproducible results in research though it includes 25 years of discussion into the fundamental distinctions between the "cardiac" pump theory, and its younger competitor the "thoracic" pump theory (Criley et al., 1976). In this theory, intrathoracic pressure changes are thought to cause forward blood flow due to collapse of thin-walled vessels at the thoracic outlets, with little concern about continued blood supply. Another aspect contributing to the dearth of fundamental change could be the use of less suitable animal models for physiological analysis. In the mean time, the survival rate remains at an unchanged $5-10 \%$.

Kouwenhoven suggested that compression on the sternum would decrease the anterior-posterior diameter of the chest, and force the heart (e.g., the left ventricle) against the spine. This would, in the presence of 
a competent mitral valve, cause forward blood flow, allowing myocardial and cerebral oxygenation. Release, as artificial diastole, would allow for ventricular filling. Currently, the chest is compressed $80-100$ times min $^{-1}$, with a force of up to $70 \mathrm{~kg}$ (Noordergraaf et al., 2005) yielding an extrapolated sternal displacement of $4-5 \mathrm{~cm}$.

In the 1980s, in the face of an ongoing fundamental discussion of "cardiac" versus "thoracic" pump, the development of adjuncts, such as active compressiondecompression (ACD-CPR) techniques generated interest in the use of analytical procedures (models). However, as Babbs (2003) noted in his review, these models never achieved the status of serious original contributions, and played only a nominal role. Retrospectively, an important opportunity for gaining fundamental physiological and patho-physiological insights into CPR may have been overlooked.

\section{Models in the Circulation}

The design of models of the closed cardiovascular loop is rooted in 1850, when Weber published his fluiddynamic model, primarily for teaching purposes (Weber, 1850). Electrical, then mathematical models followed in due course, (e.g., De Pater and Van den Berg, 1964; Attinger and Anné, 1966; Beneken and De Wit, 1967), sometimes reaching high levels of complexity (Karreman and Weygandt, 1978).

Model making in CPR was initiated in the 1980s and follows, in large part, the same line: fluid-mechanical models for illustrative purposes, and distributed electrical and mathematical models for analytical purposes. These models cover the vasculature at different levels of detail, but, unlike their predecessors have not been reported with validation under physiological conditions, a traditional prerequisite. The models rarely featured a heart that can contract and relax.

Instead, modeling was utilized predominantly to investigate or support the effectiveness of adjuncts to standard CPR. Landmarks are the addition of abdominal counterpulsation (Babbs et al., 1984) and the effect of variation of intrathoracic pressure accompanied by phased chest and abdominal compressions or fixation (Beyar et al., 1984, 1985). Halperin, evaluating the vest as a viable option to chest compressions, changed compression frequency, force and duration as major criteria to elucidate the pump mechanism (Halperin et al., 1987). Using Babbs's model (1984) the effects of arterial and venous volume loading were reevaluated by Tomaszewski and Meador (1987).
All of these interventions resulted in pressure, volume and flow alterations at multiple sites in the closed loop. For clinical, physiological and more specifically CPR-related practitioners, these models were difficult to comprehend. A number of factors may have contributed to this, such as the use of clinically unfamiliar electrical analogs, the introduction of parameter values which for the most part have not been defined in the clinical setting, and their use to support techniques superimposed on standard CPR as opposed to their use for fundamental work.

In the present study, a model has been developed and analyzed for the express purpose of promoting understanding of pressure and flow phenomena during CPR as observed in a wide range of experimental and clinical reports. We concentrate on the core of a larger model. This report will focus on computer experiments on the left ventricle provided with a preload and an arterial load. Pressures, flows and volumes will be displayed and analyzed. Negative volumes, a modeling artifact that has anecdotally appeared for at least half a decade will also be discussed with presentation of a method to guard against this flaw. Current clinical concerns and developments will be touched upon.

\section{METHODS AND PROCEDURES}

In this report the focus is on the left ventricle, equipped with adjustable preload and arterial load, a small but vital part of the circulatory system. It will be modeled quantitatively, first for control conditions, then under various pathological conditions related to CPR, including cardiac arrest status in which the myocardial compliance changes, as seems to occur during progression of CPR. The motive for performing a model study is to have access to experiments not executable in the human, and serve to gain insight into classic as well as adjunct theories for CPR (Noordergraaf et al., 2006).

Under control conditions, a number of routine responses of the ventricle are demonstrated as validation of its physiological properties. Three pathological circumstances, a noncontracting ventricle with competent valves under application of external compression, a normally contracting ventricle, operating as an open conduit, and a noncontracting ventricle operating as an open conduit with external compression are reported.

The model is a reduced, lumped parameter model, and is represented as a mixed system of differentialalgebraic equations (DAE). This system of DAE's has been solved with Mathematica (Wolfram, 2003). The core 
(a)

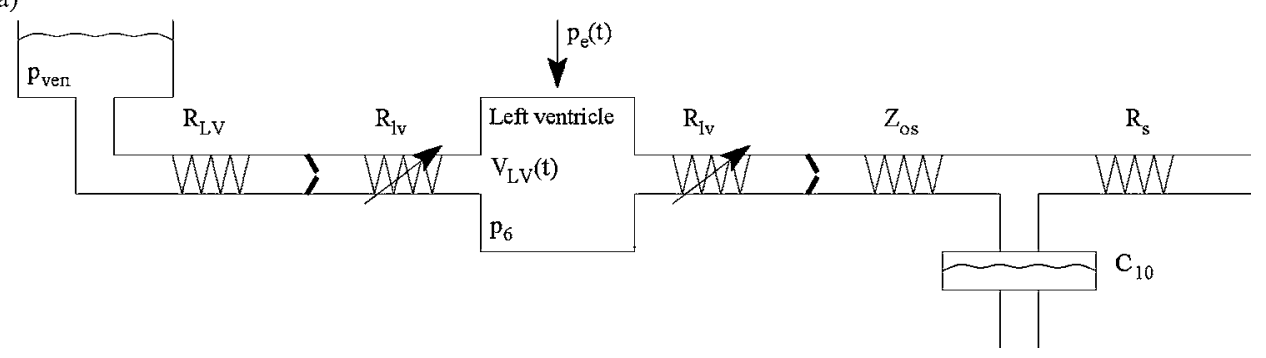

(b)

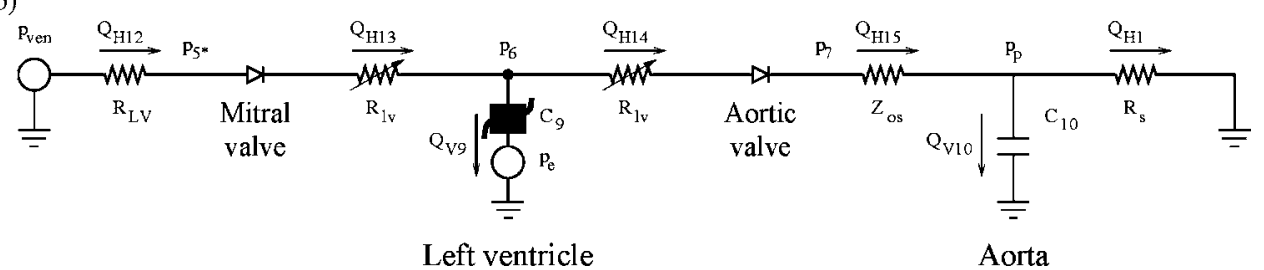

Figure 1. (a) Fluid mechanical representation of the left ventricle with preload ( $p_{\text {ven }}$ at the far left), and arterial load (the three elements on the far right), plus a facility to compress the ventricle $\left(p_{\mathrm{e}}(t)\right)$. $V_{\mathrm{LV}}(t)$ denotes left ventricular volume at time $t$, and $R_{\mathrm{LV}}$ a ventricular inflow resistance. For the function of the two variable resistors marked $R_{\mathrm{lv}}$, consult the caption of Fig. 9. (b) Electrical representation of the fluid mechanical model in (a) with the valves identified by name. Local flows $Q$ are marked with the arrows indicating their positive directions.

model consists of 12 variables, including seven flows and four pressures. Figure 1(a) shows the model utilizing fluidmechanical symbols, Fig. 1(b) using the more specific electrical symbols (Palladino et al., 2000). Similarity in vascular layout is evident among the models listed above and the core of the model presented here.

Particular attention will be devoted to the role played by the recently discovered principle of impedance-defined flow (Moser et al., 1998). This principle holds that blood flow around the cardiovascular circuit can be generated by any of its compressible or distensible parts. The mechanism can be contraction and relaxation, compression and release (e.g. CPR), shaking the body, or changing the gravitational field. The theory holds for conditions with and without functional valves, as well as making a distinction between sloshing of blood and actual effective forward flow, allowing the quantification of antegrade and retrograde stroke volumes over any valve or valve ostium. Stroke volume can thereby be defined in the classic sense, while antegrade volume is defined as the area under the positive part of the ejection curve, retrograde flow being the area under the negative part of the injection curve These distinctions led to appreciation of the difference between sloshing of blood and flow around the cardiovascular circuit.

The left ventricle (Fig. 1(a)) is identified in conjunction with its preload in the form of a constant pressure source, $p_{\text {ven }}$, implying a large venous reservoir, such as occurs in a normo- to hypervolemic, supine, human, and an arterial load, represented by the three element modified windkessel to the far right of the ventricle (Westerhof and Noordergraaf, 1969). The mitral and aortic valves, modeled as free-flowing two dimensional leaflets are marked, as is the facility to apply periodic external compression and relaxation, $p_{\mathrm{e}}(t)$. The valves are not modeled as electrical diodes, in order to allow internal definition of movement. For simplicity, the external pressure is interpreted as acting directly and selectively on the ventricle.

The same features appear in Fig. 1(b), with $R_{\mathrm{LV}}$ denoting a (small) inflow resistance, $Z_{\mathrm{os}}$ the characteristic impedance of the aorta, $R_{\mathrm{S}}$ the systemic peripheral resistance and $\mathrm{C}_{10}$ the arterial compliance. Pressures are marked $p$. Flows, $Q$, with their positive directions, are defined in each section. Volumes are marked $V$. Ventricular pressure as a function of time, $t$, is denoted $p_{6}(t)$ and similarly for other variables. The initial parameter values are those found in the physiological literature.

Care was taken to model the normal function of the circulation to meet physiological requirements. The ejection effect, the influence of ventricular outflow on ventricular pressure was added, even though it is unknown if this is an effect seen under CPR conditions.

The set of equations for this model may be found in Appendix 1, while the numerical values of the system's 


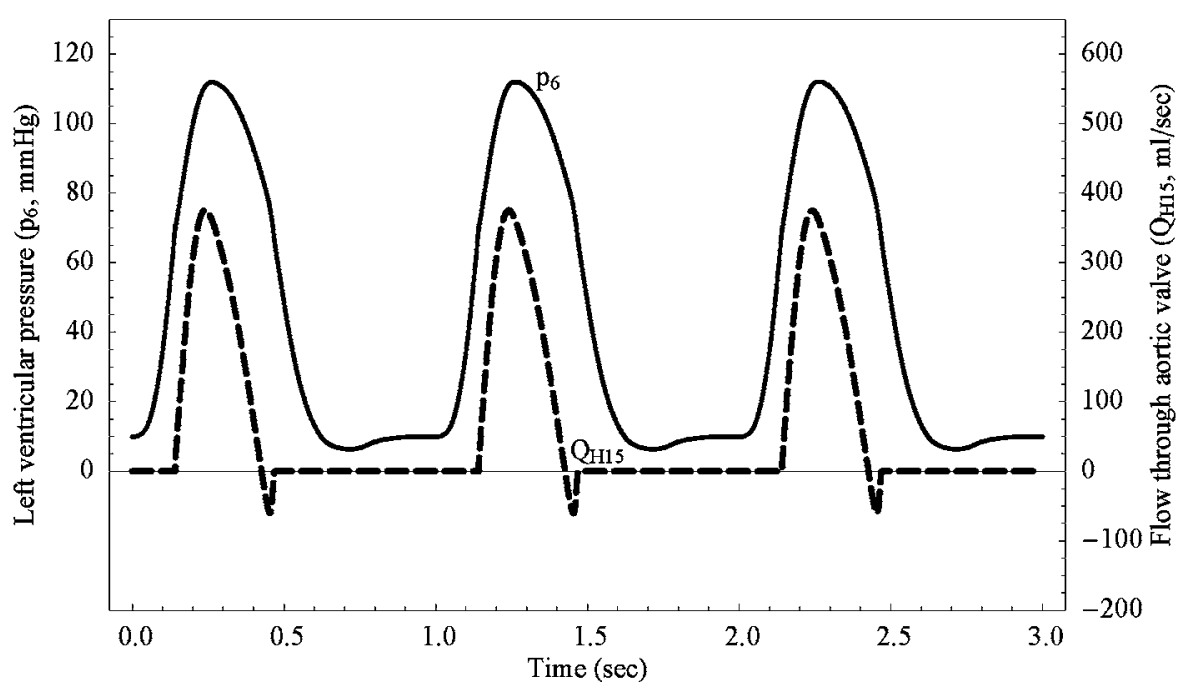

Figure 2. Ventricular pressure $\left(p_{6}(t)\right.$, solid) and outflow through the aortic valve $\left(Q_{\mathrm{H} 15}(t)\right.$, dashed), with the ejection effect. Stroke volume $V_{\mathrm{sLV}}$ is $64 \mathrm{~mL}$, ejection fraction is $52 \%$, venous pressure is $10 \mathrm{mmHg}$, and $R_{\mathrm{S}}$ is $1.2 \mathrm{mmHg} \mathrm{s} \mathrm{mL}^{-1}$.

properties, required to solve the equations for flows, pressures, and volumes may be found in Appendix 2.

\section{RESULTS}

In the model, under control conditions, with definition of preload, normal myocardial contractility $\left(F_{\mathrm{LV}}\right)$ and the load impedance by the aorta, physiological output curves for flow and pressure are demonstrated in Fig. 2. This figure displays the left ventricular pressure and ejection flow including the so-called ejection effect (Danielsen et al., 2000) for a heart rate of $60 \mathrm{~min}^{-1}$, a venous pressure $\left(p_{\text {ven }}\right)$ of $10 \mathrm{mmHg}$ and $R_{\mathrm{S}}$ at $1.2 \mathrm{mmHg} \mathrm{s} \mathrm{mL}^{-1}$. The current model continues where the former is restricted to the introduction of the ejection effect into the outflow curve, incorporating this into the theory of impedance defined flow. The ejection effect embodies the influence of outflow on ventricular pressure. Its inclusion tends to make both pressure and flow downstrokes more convex. The stroke volume is $64 \mathrm{~mL}$, the ejection fraction $52 \%$. The summaries of a preload ranging from 4 to $20 \mathrm{mmHg}$ and of peripheral resistance changes from 0.6 to $2.2 \mathrm{mmHg} \mathrm{s} \mathrm{mL}^{-1}$ are shown in Fig. 3(a) and (b), respectively, with the other parameters held as above. The stroke volume (solid line), defined as net output, is shown with the antegrade stroke volume, $\left(Q_{\mathrm{H} 15}\right.$, dashed line), and reflects upon the competence of the aortic valve during relaxation. The enddiastolic volume (dash-dot line) is also shown.

By setting $F_{\mathrm{LV}}$ (Appendix 1) equal to zero, the ventricle becomes asystolic. Its myocardial properties become dependent on its diastolic function $\left(a_{\mathrm{LV}}\right.$ and $\left.b_{\mathrm{LV}}\right)$ and, as CPR is started, on the external pressure $p_{\mathrm{e}}(t)$ applied to the outside of the ventricle. In order to allow direct comparison with the physiological validation, the compression frequency was chosen at $60 \mathrm{~min}^{-1}$ as opposed to the 80 100 compressions $\mathrm{min}^{-1}$ in current clinical practice. The duty cycle, the time relationship between compression and relaxation as a continuous sine wave, is $50 \%$, as clinically appropriate. The $p_{\mathrm{e}}(t)$ curve is shown in the top of Fig. 5a for reference purposes, with $p_{\text {emin }}$ being equal to zero. Figure 4 depicts stroke volume as a function of the maximal external pressure during its systolic phase, while in Fig. $5(\mathrm{a}-\mathrm{c})$ the $p_{\text {emax }}(t)$ increases from 20 to 40 to $60 \mathrm{mmHg}$, respectively, while ventricular pressure $\left(p_{6}\right)$ is plotted synchronously with mitral inflow and aortic outflow. These same pressure and flow characteristics are displayed in Fig. 6 for a less compliant (stiffened) ventricle or so-called stone heart as may happen after the first minutes of asystole. The mitral and aortic valves are allowed to move freely and are seen to be competent in all cases above.

With respect to the controversy in whether the (left) heart is a conduit during CPR, further experiments can be performed by defining incompetent valves within the model. Figure 7 illustrates the dependence of stroke volume $\left(Q_{\mathrm{H} 15}\right)$, antegrade stroke volume, and end diastolic volume on preload, $p_{\text {ven }}$ with a normally contracting ventricle. The percentage difference between antegrade stroke volume and stroke volume increases as $p_{\text {ven }}$ increases. Comparison of Fig. 3(a) with Fig. 7 demonstrates a reduction of stroke volume by $7 / 8$. The dependence of 

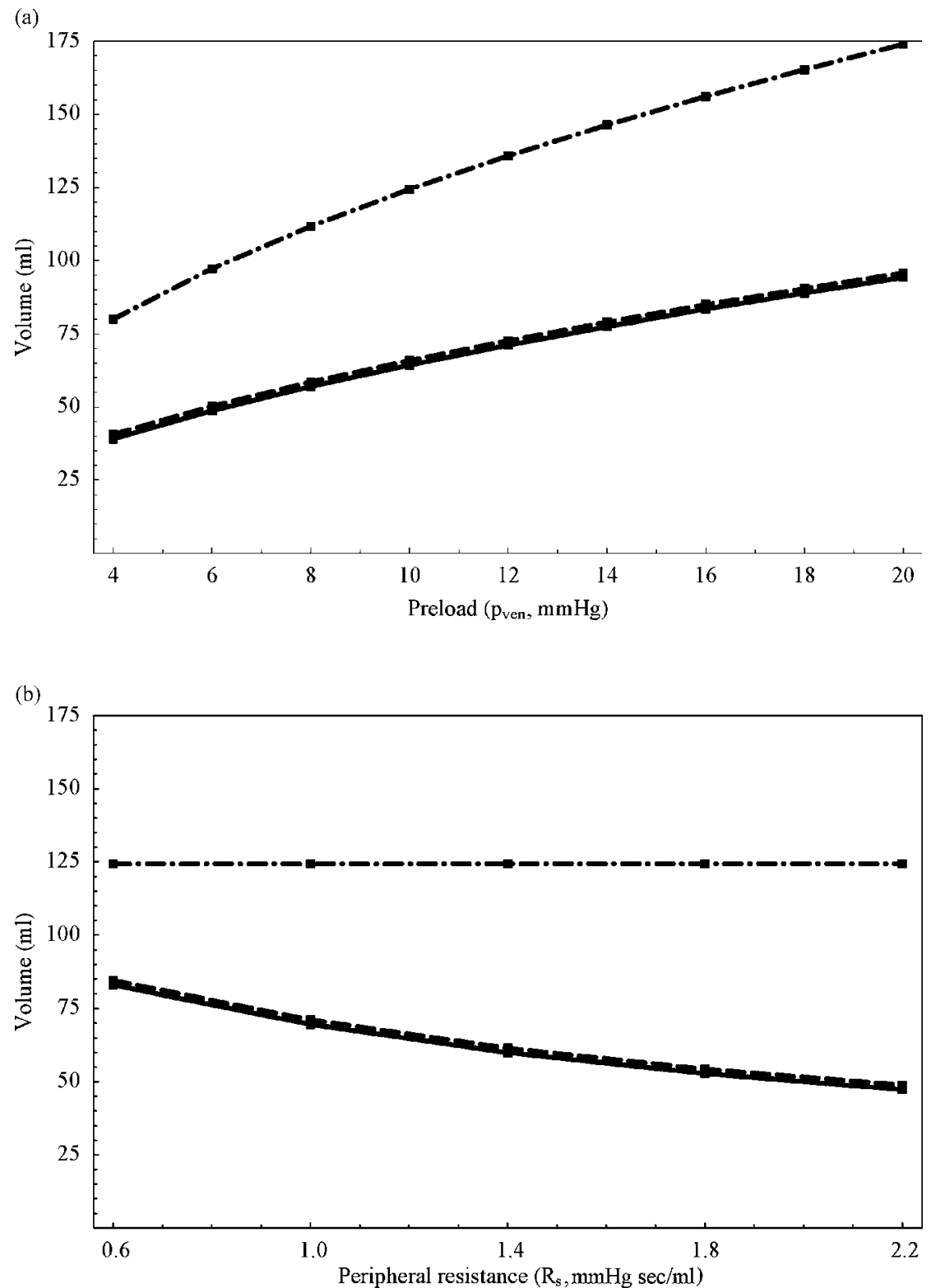

Figure 3. (a) Stroke volume (solid), antegrade stroke volume (dashed), and end diastolic volume (dash-dot), versus preload ( $\left.p_{\text {ven }}\right)$. Heart rate is 60 beats per minute. (b) Stroke volume (solid), antegrade stroke volume (dashed) and end diastolic volume (dash-dot), versus systemic peripheral resistance $\left(R_{\mathrm{s}}\right)$. Note: the horizontal axis runs from 0.6 to 2.2 in steps of 0.4 . Heart rate $60 \mathrm{bpm}$.

left ventricular volume, ventricular pressure, flow through the mitral ostium and flow through the aortic root in a normally contracting valveless ventricle with $p_{\text {ven }}$ at $10 \mathrm{mmHg}$ is graphed in Fig. 8(a). Time averaged values for the two flows are $7.8 \mathrm{~mL} / \mathrm{s}$. Figure $8 \mathrm{~b}$ shows the time courses of the same quantities when the venous pressure is increased to $20 \mathrm{mmHg}$. Time averaged values for the two flows increases to $15 \mathrm{~mL} / \mathrm{s}$. After removal of the "functional" valves, the mitral and aortic ostia retain their defined area. The inflow resistance, $R_{\mathrm{LV}}$, and the characteristic impedance in the aorta remain unaltered.

The removal of valves may also be directly applied in the CPR situation. Stroke volume, antegrade stroke volume, and retrograde stroke volume (the area under one cycle of the negative part of the $Q_{\mathrm{H} 13}$ curve) as a representation of regurgitant flow into the atrium, as well as end diastolic volume are displayed as a function of venous pressure in Fig. 9. At a venous pressure of 


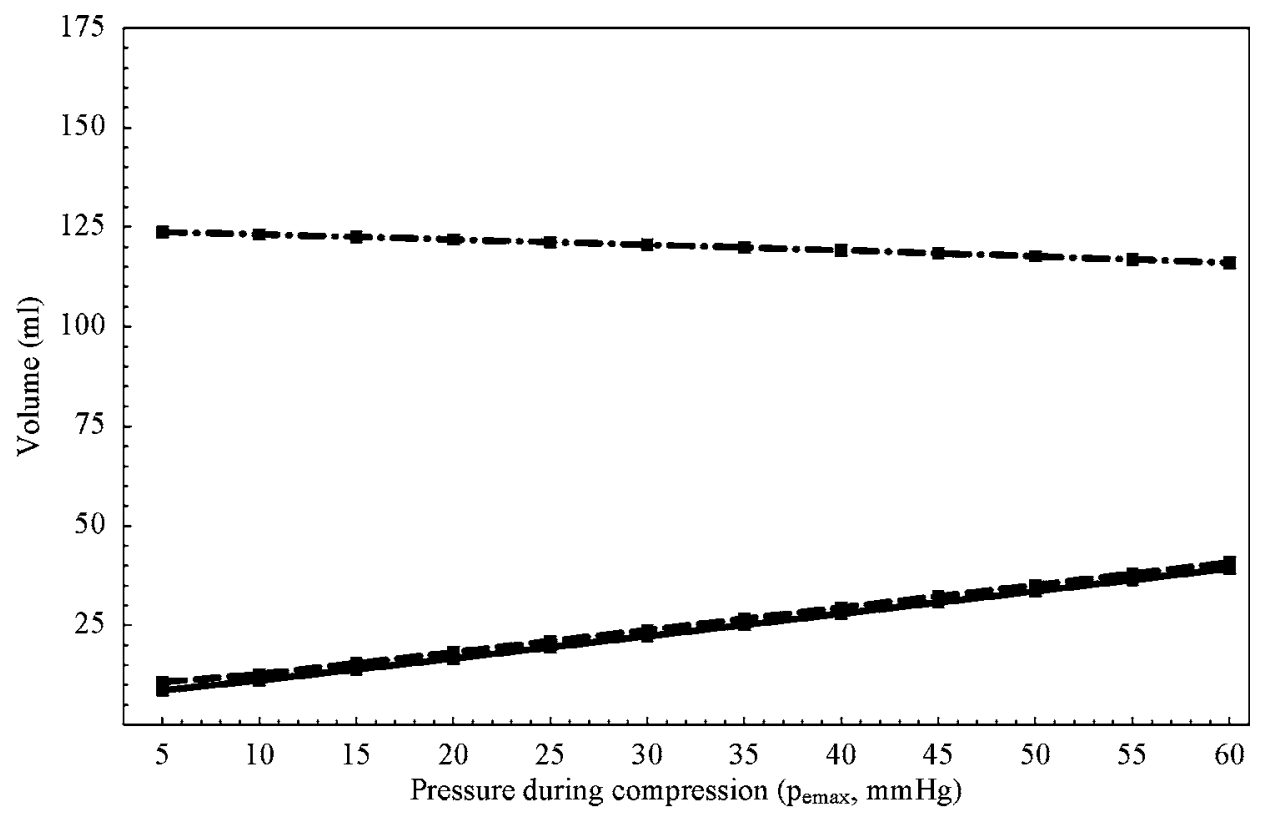

Figure 4. Stroke volume (solid), antegrade stroke volume (dashed), and end diastolic volume (dash-dot), versus peak compression pressure ( $p_{\mathrm{emax}}$ ). Compression rate is $60 \mathrm{cpm}$.

$10 \mathrm{mmHg}$, Fig. 10(a) displays the left ventricular volume, ventricular pressure, flow through the mitral ostium and through the aortic root for a peak compression pressure of $60 \mathrm{mmHg}$. Time averaged values for both flows are $7.5 \mathrm{~mL} / \mathrm{s}$. Antegrade and retrograde stroke volumes are 12 and $97 \mathrm{~mL}$, respectively, denoting prominent sloshing on the venous side. Figure 10(b) displays the same time functions for the same conditions, but for a venous pressure of $20 \mathrm{mmHg}$. Time averaged values for both flows increased to $15 \mathrm{~mL} / \mathrm{s}$, the antegrade and retrograde stroke volumes to 21 and $149 \mathrm{~mL}$, respectively. The venous sloshing increases proportionately.

In the original computer experiments for Figs. 9 and 10 , ventricular volumes were sometimes found to become negative. Other investigators have mentioned, but left unpublished, similar observations for several years. Since negative ventricular volume is a physical impossibility, its origin was sought and remedied. The remedy is incorporated in the figures.

\section{DISCUSSION}

Modeling procedures are utilized in view of the fact that they permit experiments to be performed under carefully controlled conditions and allow manipulations not acceptable for application to the animal or human studies (Noordergraaf et al., 2005). It permits the use of selective pathology: the totally healthy being with an asystolic heart but also the normal heart without functional valves. The small model depicted in Fig. 1(a) comprises the left ventricle in fluid mechanical representation. The preload is defined by an adjustable, constant venous pressure; the arterial load is cast in the form of a three element modified windkessel (Westerhof and Noordergraaf, 1969). The ventricle is capable of normal contraction and relaxation with an adjustable frequency, and can be made passive (Danielsen et al., 2000). Inlet and outlet valves (representing mitral and aortic) may be included or excluded. The time dependence of variable pressures is presented in Appendix 1, with the parameter values in Appendix 2. Steady state solutions to the set of equations are obtained through a numerical solution method.

Experiments, for the validation of the model, shown in Figs. 2 and 3 demonstrate the standard patterns of behavior in terms of pressure and ejection flow, and sensitivity to preload and to peripheral resistance of stroke volume, and end diastolic volume. This evidence is deemed to indicate that the ventricle behaves normally.

When the ventricle looses its capability to contract, modeled by setting $F$ in Appendix 1 to zero, intra thoracic pressure, $p_{\mathrm{e}}(t)$ is applied as an external pressure to the ventricle with a $50 \%$ duty cycle, as displayed at the top of Fig. 5(a).

The model allows an understanding of Kouwenhoven's theory, in conjunction with increasing clinical, but still mostly empirical concerns about 

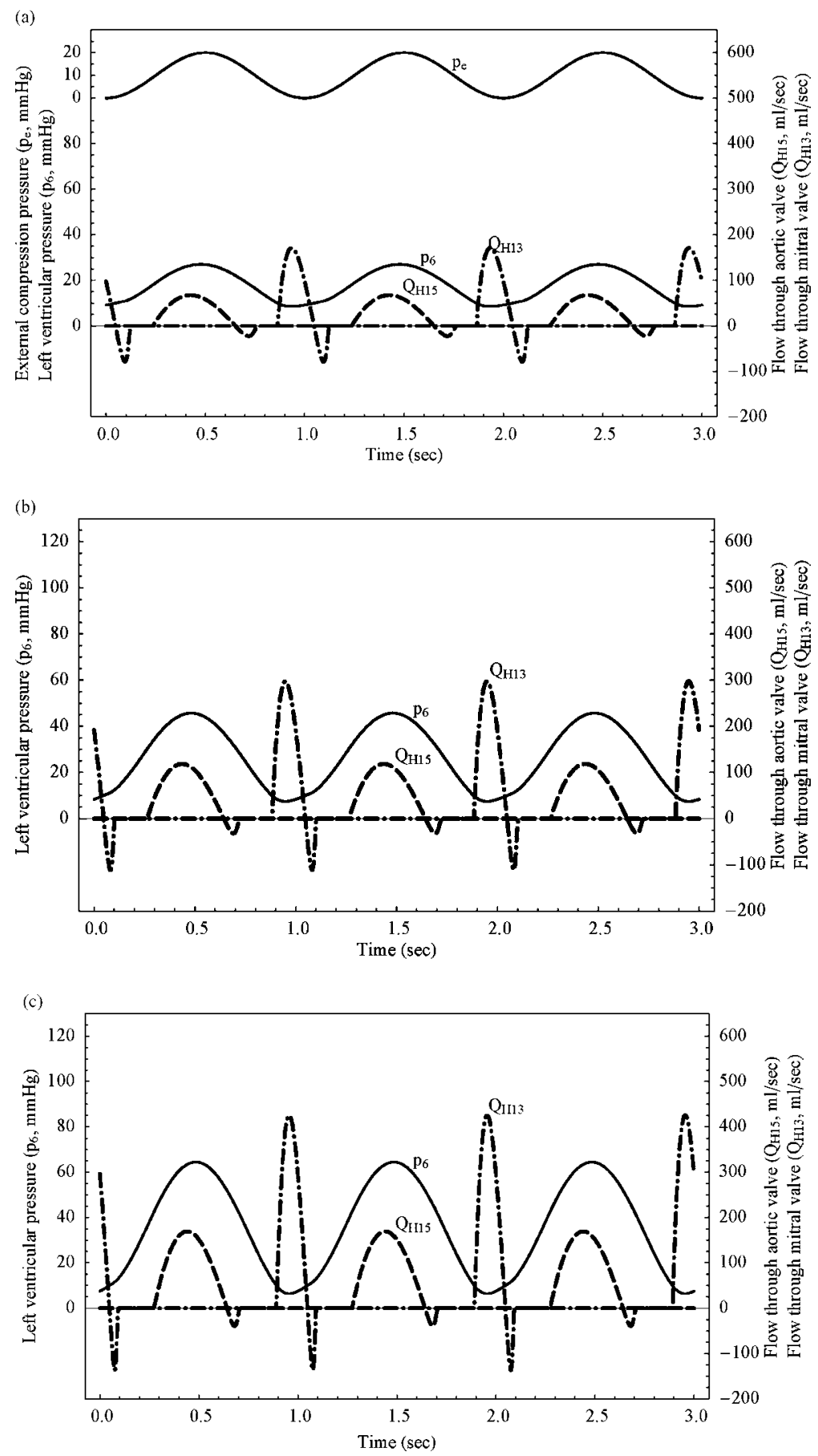

Figure 5. (a) Left ventricular pressure $\left(p_{6}(t)\right.$, solid), inflow through the mitral valve $\left(Q_{\mathrm{H} 13}(t)\right.$, dash-dot) and outflow through the aortic valve $\left(Q_{\mathrm{H} 15}(t)\right.$, dashed) for a noncontracting ventricle exposed to a compression pressure $p_{\mathrm{emax}}$ of $20 \mathrm{mmHg}$. The time average values over one period of $Q_{\mathrm{H} 13}$ and $Q_{\mathrm{H} 15}$ are $17 \mathrm{~mL} / \mathrm{s}$. The time course of $p_{\mathrm{e}}(t)$ is displayed at the top. Venous pressure is $10 \mathrm{mmHg}$ in all three displays. In other figures $p_{\mathrm{emax}}$ may be different as defined in the pertinent captions. (b) Left ventricular pressure $\left(p_{6}(t)\right.$, solid), inflow through the mitral valve $\left(Q_{H 13}(t)\right.$, dash-dot) and outflow through the aortic valve $\left(Q_{\mathrm{H} 15}(t)\right.$, dashed) for a noncontracting ventricle exposed to a compression pressure $p_{\mathrm{emax}}$ of $40 \mathrm{mmHg}$. The time average values over one period of $Q_{\mathrm{H} 13}$ and $Q_{\mathrm{H} 15}$ are $28 \mathrm{~mL} / \mathrm{s}$. (c) Left ventricular pressure ( $p_{6}(t)$, solid), inflow through the mitral valve $\left(Q_{\mathrm{H} 13}(t)\right.$, dash-dot) and outflow through the aortic valve $\left(Q_{\mathrm{H} 15}(t)\right.$, dashed) for a noncontracting ventricle exposed to a compression pressure $p_{\mathrm{emax}}$ of $60 \mathrm{mmHg}$. The time average values over one period of $Q_{\mathrm{H} 13}$ and $Q_{\mathrm{H} 15}$ are $88 \mathrm{~mL} / \mathrm{s}$. 


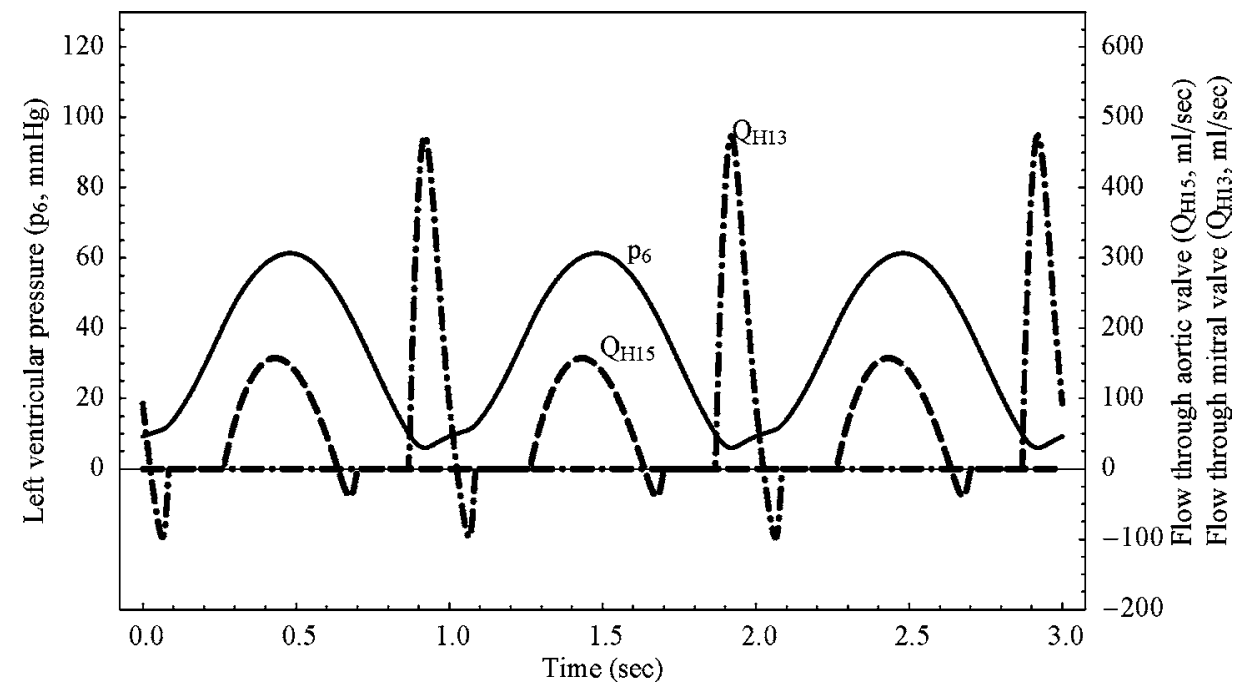

Figure 6. As Fig. 5 for a stiffer relaxed ventricle $\left(a_{\mathrm{LV}}=40 \times 10^{-4}\right.$ instead of $7 \times 10^{-4} \mathrm{mmHg} / \mathrm{mL}^{2}$. Left ventricular pressure $\left(p_{6}(t)\right.$, solid $)$, inflow through the mitral valve $\left(Q_{\mathrm{H} 13}(t)\right.$, dash-dot) and outflow through the aortic valve $\left(Q_{H 15}(t)\right.$, dashed) with a compression pressure $p_{\mathrm{emax}}$ of $70 \mathrm{mmHg}$. The time average values of $Q_{\mathrm{H} 13}$ and $Q_{\mathrm{H} 15}$ are $45 \mathrm{~mL} / \mathrm{s}$ over one period.

ventricular filling in the asystolic heart. It confirms recent work in swine by Klouche et al. (2002) who suggest that current techniques may not be suitable after only $8 \mathrm{~min}$ of CPR. In addition, it allows hemodynamic insights into contradictory echocardiographic studies which have been performed in patients undergoing CPR. While 77 patients have been described, the compression force has yet to be objectified in conjunction with valve motion and output (Noordergraaf et al., in press-a). These studies tend to show that subtotal closure of the mitral or aortic valve is associated with minimal forward flow, as the model suggests.

This model suggest that the "cardiac" pump theory, in its fundamental form, can be applied, but that this offers

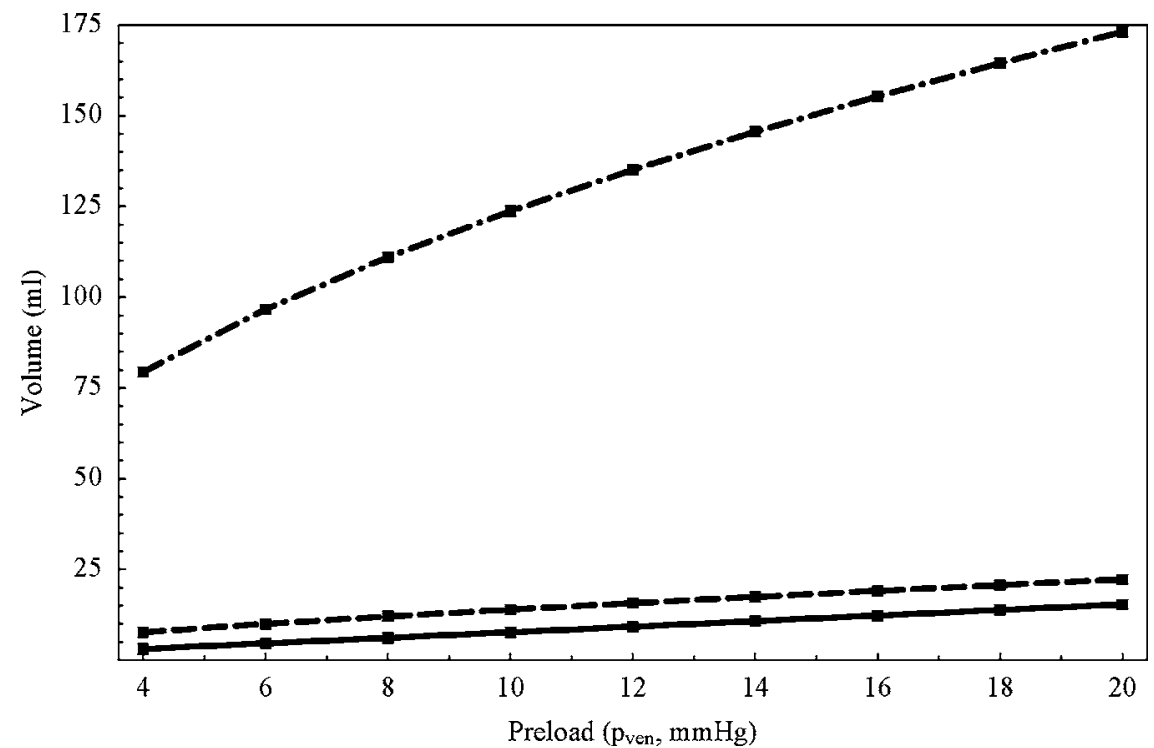

Figure 7. Stroke volume (solid), antegrade stroke volume (dashed), and end diastolic volume (dash-dot), versus preload ( $\left.p_{\text {ven }}\right)$ in a normally contracting ventricle after removal of both valves. 

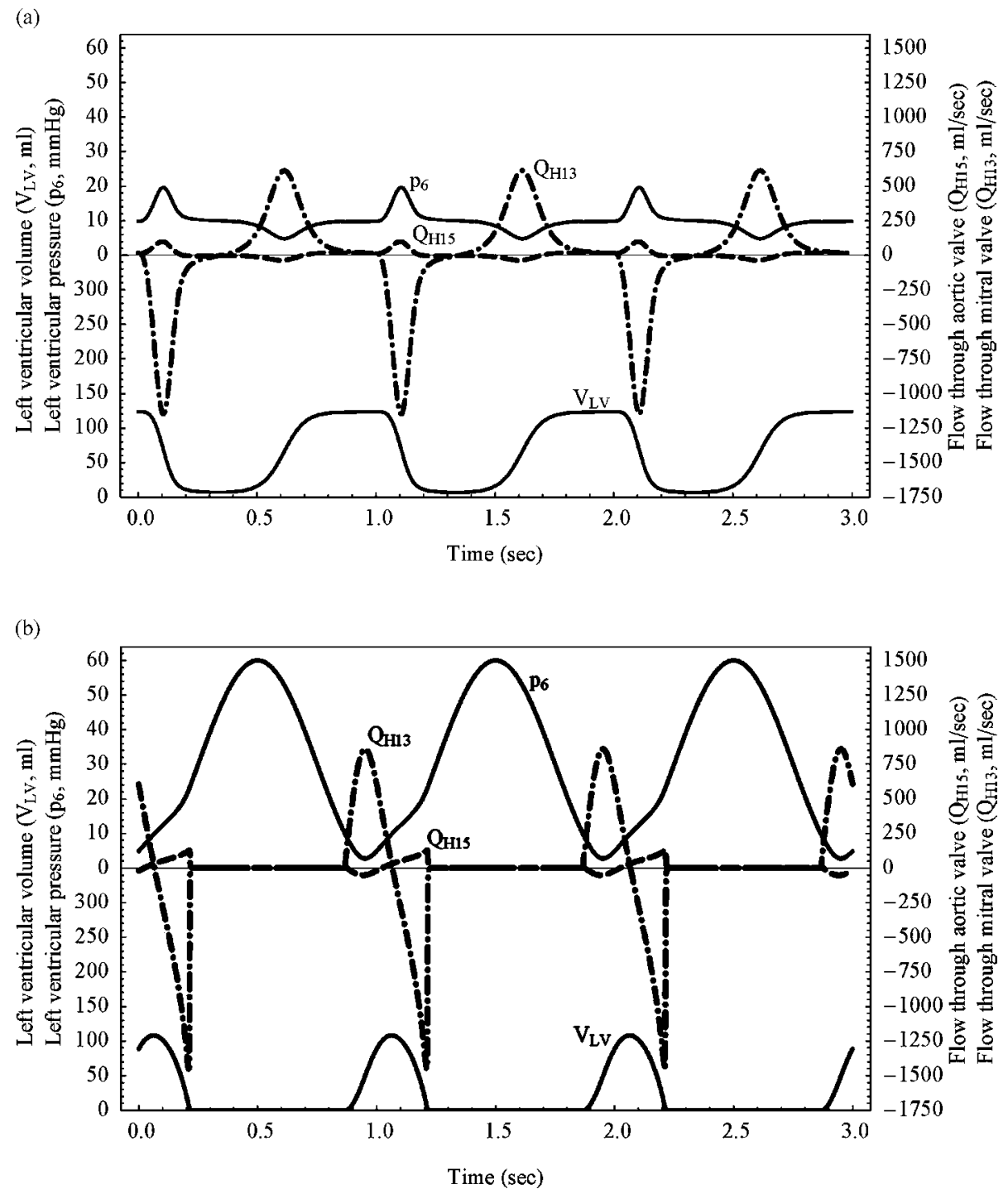

Figure 8. (a) Left ventricular volume $\left(V_{\mathrm{LV}}(t)\right.$, solid), ventricular pressure $\left(p_{6}(t)\right.$, solid), flow through the mitral valve ostium $\left(Q_{\mathrm{H} 13}(t)\right.$, dash-dot) and flow through the aortic root $\left(Q_{\mathrm{H} 15}(t)\right.$, dashed), in a normally contracting valveless ventricle with $p_{\text {ven }}$ at $10 \mathrm{mmHg}$. The time average values over one period of $Q_{\mathrm{H} 13}$ and $Q_{\mathrm{H} 15}$ are $7.8 \mathrm{~mL} / \mathrm{s}$. (b) Left ventricular volume $\left(V_{\mathrm{LV}}(t)\right.$, solid), ventricular pressure ( $p_{6}(t)$, solid), flow through the mitral ostium $\left(Q_{\mathrm{H} 13}(t)\right.$, dash-dot) and flow through the aortic root $\left(Q_{\mathrm{H} 15}(t)\right.$, dashed), in a normally contracting valveless ventricle with $p_{\mathrm{ven}}$ at $20 \mathrm{mmHg}$. The time average values over one period of $Q_{\mathrm{H} 13}$ and $Q_{\mathrm{H} 15}$ are $15 \mathrm{~mL} / \mathrm{s}$.

limited forward flow. The left ventricle is compressed by an outside force without interfering with the cardiac valves, and without influencing filling pressures, as described by Kouwenhoven et al. It ignores the viscoelastic properties of the chest when applying $p_{\mathrm{e}}$ and describes the ventricle as if it supported on a firm surface. Clinically, whether the support actually exists is still controversial, although reports have describing the heart to be fixed within the mediastinum by the pericardium (Kouwenhoven et al., 1960; Deshmukh et al., 1985). The improved effect of in- creasing $p_{\mathrm{e}}(t)$ is in line with experimental findings (Ornato et al., 1989). A limitation is the compression frequency of $1 \mathrm{~Hz}$, while current clinical practice is 100 compressions $\mathrm{min}^{-1}$ and the higher frequency may improve cardiac output (Maier et al., 1986)

As Fig. 4 shows, stroke volume improves by increasing the level of external pressure (Fig. $5(\mathrm{a}-\mathrm{c})$ ) when both valves operate normally. Stroke volume suffers slightly when the ventricle's passive elastic properties become less compliant (stone heart; Fig. 6). 


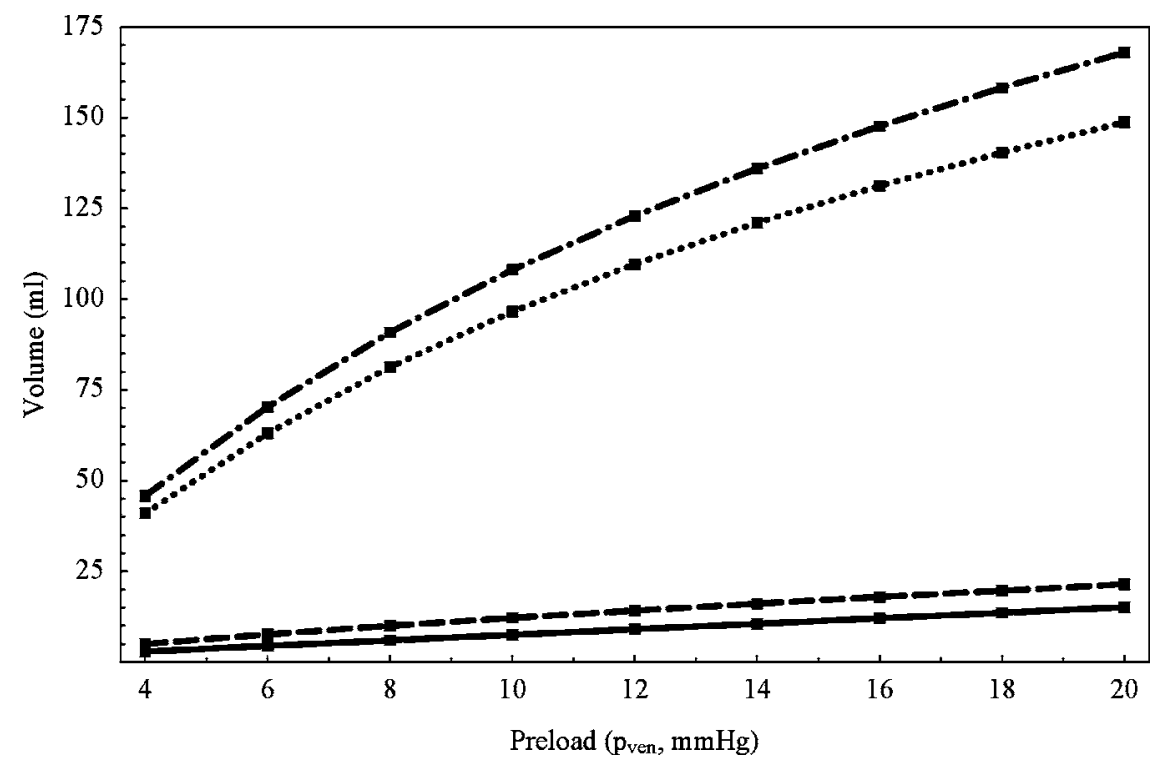

Figure 9. A detailed explanation and a remedy may be found in the discussion. Figures 9, 10(a) and (b) are computer solutions obtained after the remedy was instituted. Stroke volume (solid), antegrade stroke volume (dashed), retrograde stroke volume, the area under the negative $Q_{\mathrm{H} 13}$ curve (dotted), and end diastolic volume (dash-dot) versus preload $\left(p_{\text {ven }}\right)$ for a noncontractile valveless ventricle.

Analysis of the conduct of the model requires an understanding of early work by Harvey and Liebau. William Harvey, in his 1628 treatise entitled "De Motu Cordis et Sanguinis" assigned the movement of blood around the cardiovascular circuit to the valve equipped pumping heart alone (Harvey, 1628). During the 1950s, the physician Liebau (Liebau, 1954) challenged this position by demonstrating that valveless, fluid dynamic, closed loop models of his own construction could generate average flow around the closed loop as a result of periodic local compression and release. Despite support by fluid-dynamicists, Liebau was unable to offer an explanation and interest waned until a quantitative interpretation was published in 1998 (Moser et al., 1998). The nonuniform distribution of impedance around the cardiovascular circuit proved to be the secret and the phenomenon was called impedance-defined flow. Harvey's observations of the heart and its valves may be seen as a special case, and consequently, both concepts could be unified within impedance-defined flow (Noordergraaf, 2006). Impedance-defined flow also applies to open systems such as in Fig. 1.

In classic models of the cardiovascular system, flow was generated by a pressure difference between the arteries and veins, such as has been described during the first minutes of circulatory collapse. Parameter values were adapted to match experimentally derived information.
If a ventricle contracts and relaxes, its blood volume can, in principle, escape in two directions during contraction and return from two directions during relaxation. If it were the only mechanism operating to move blood, then flow in either direction would be equal to the pressure difference between a selected point and the ventricle, divided by the resistance (impedance) between these two points.

The situation in Fig. 1 is slightly more complicated by the presence of a venous pressure source, $p_{\text {ven }}$, which may be responsible for a part of the observed flow. These two flows may be identified separately, as illustrated in Fig. 8 (a valveless ventricle). Here, $p_{\text {ven }}$ generates a flow of $(10-0) / 1.2 \approx 8 \mathrm{~mL} / \mathrm{s}$, which is equal to the average calculate flow through the model. This same analysis for a venous contribution applies in Fig. 10. In both cases the superimposed oscillations are due to direct ventricular, cyclic, application of $p_{\mathrm{e}}(t)$, as would be done during clinical CPR (Ornato et al., 1989). This means that a heart contracting without valves, or during CPR applied to a ventricle without competent valves, forces an insignificant amount of blood through the peripheral resistance. Essentially, the model demonstrates that all flow passing $R_{\mathrm{S}}$ is due to the venous pressure. In Figs. 8 and 10 sloshing of blood is a second spectacular event: large inflow and outflow signals follow each other on the venous side during a single heart beat. As a result, the large flow pulses fail to contribute to transportation. 
(a)
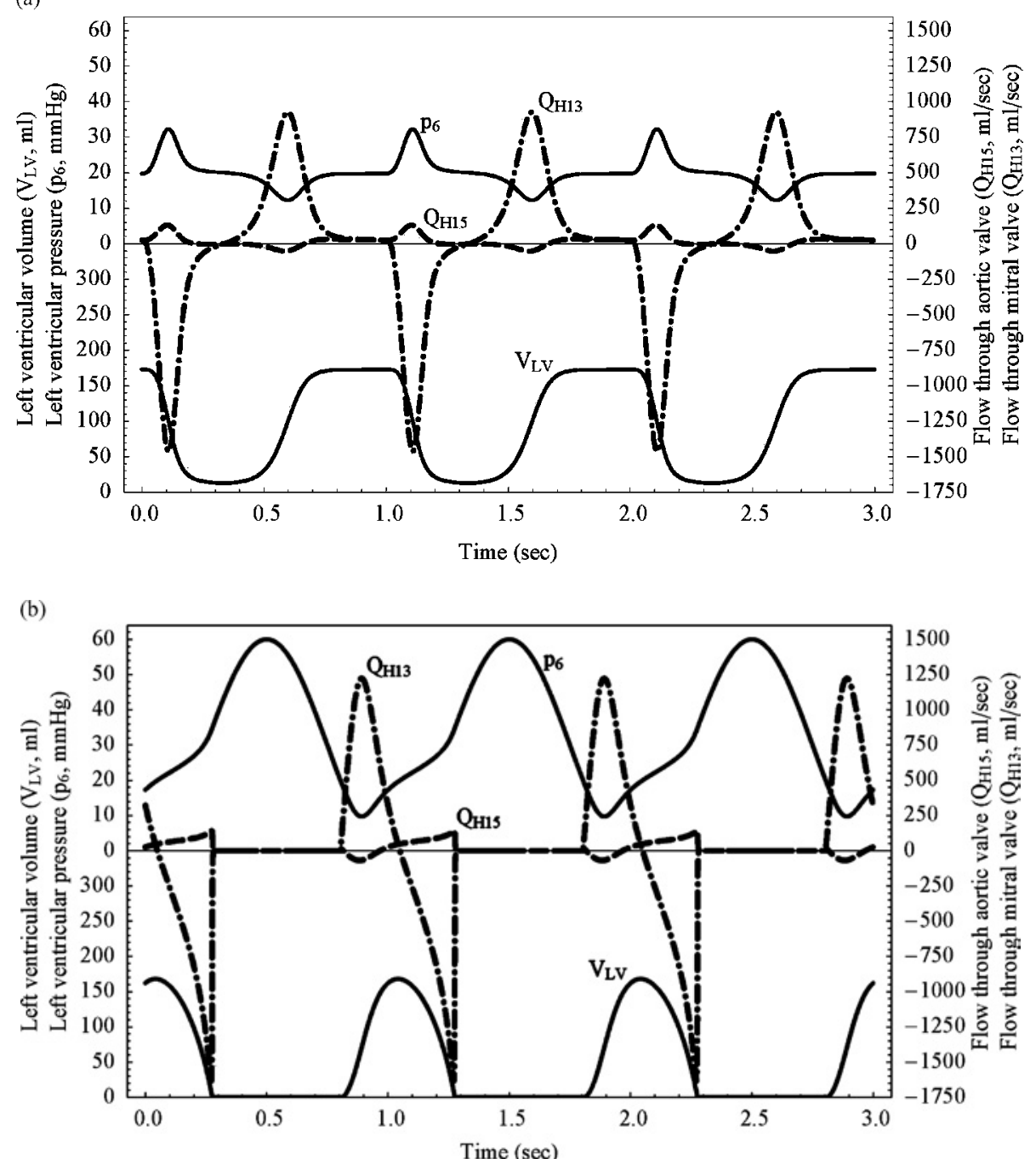

Figure 10. (a) Left ventricular volume $\left(V_{\mathrm{LV}}(t)\right.$, solid), ventricular pressure $\left(p_{6}(t)\right.$, solid), flow through the mitral valve ostium $\left(Q_{\mathrm{H} 13}(t)\right.$, dash-dot $)$ and flow through the aortic root $\left(Q_{H 15}(t)\right.$, dashed) for a noncontracting valveless ventricle, with a peak compression pressure of $60 \mathrm{mmHg}$ and $p_{\text {ven }}$ at $10 \mathrm{mmHg}$. The time average values of $Q_{\mathrm{H} 13}$ and $Q_{\mathrm{H} 15}$ are $7.5 \mathrm{~mL} / \mathrm{s}$. Antegrade stroke volume is $12 \mathrm{~mL}$, retrograde stroke volume is $97 \mathrm{~mL}$. Note prominent sloshing on the venous side. (b) Left ventricular volume $\left(V_{\mathrm{LV}}(t)\right.$, solid), ventricular pressure $\left(p_{6}(t)\right.$, solid), flow through the mitral valve ostium $\left(Q_{\mathrm{H} 13}(t)\right.$, dash-dot $)$ and flow through the aortic root $\left(Q_{\mathrm{H} 15}(t)\right.$, dashed) for a noncontracting valveless ventricle, with a peak compression pressure of $60 \mathrm{mmHg}$ and $p_{\text {ven }}$ at $20 \mathrm{mmHg}$. The time average values of $Q_{\mathrm{H} 13}$ and $Q_{\mathrm{H} 15}$ are $15 \mathrm{~mL} / \mathrm{s}$. Antegrade stroke volume is $21 \mathrm{~mL}$, retrograde stroke volume is $149 \mathrm{~mL}$. Note prominent sloshing on the venous side.

This contrasts strongly with the results in Figs. 2 and 5 , where the valves are competent. In these illustrations the ventricles generate all the flow through the peripheral resistance, without a contribution by venous pressure since at least one valve is closed at any one time. The role of $p_{\text {ven }}$ is limited to filling the ventricle.

Figure 11 shows a basic sketch of measured pressure-volume relations for the left ventricle. The rela- tion may be formulated mathematically by

$$
p_{6}=a_{\mathrm{LV}}\left(V_{\mathrm{LV}}-b_{\mathrm{LV}}\right)^{2}(1)
$$

for a relaxed ventricle $\left(F_{\mathrm{LV}}=0\right.$, Appendix 1). The function is nonlinear, and becomes zero for $V_{\mathrm{LV}}=b_{\mathrm{LV}}$. For larger values of $V_{\mathrm{LV}}$ ventricular pressure is positive, for smaller ones negative (broken line, indicating suction). Therefore, for $V_{\mathrm{LV}}>b_{\mathrm{LV}}, a_{\mathrm{LV}}$ must be positive, for 


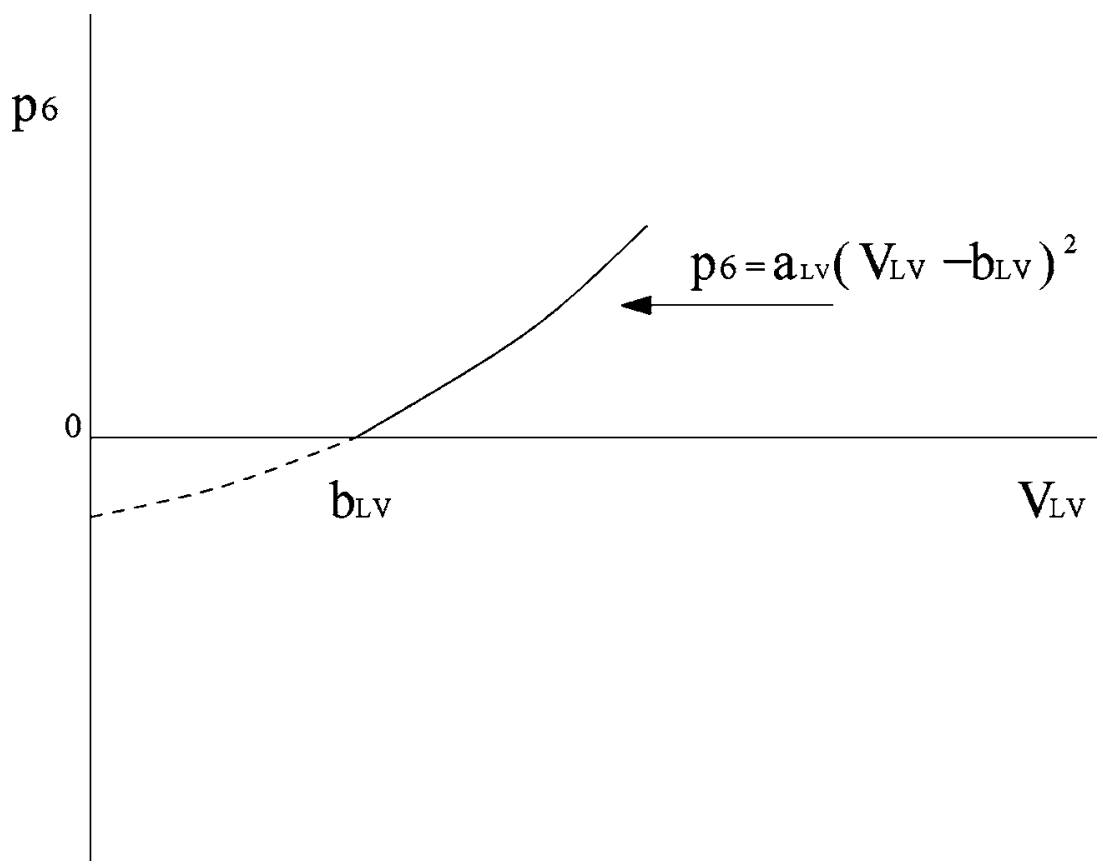

Figure 11. Pressure-volume relationships in the left ventricle. Description of the conduct of the left ventricle as a pressure-volume relationship, when the ventricle is passive. Demonstrates the principle suggested by Galenus, with "suction" of the ventricle when volumes are very low. $p_{6}=$ pressure in the left ventricle, $A_{\mathrm{lv}}=$ a measure of elastance of the left ventricle, $b_{\mathrm{lv}}=$ volume of the left ventricle, with $\mathrm{b}$ is the point at which the pressure is zero, $V_{\mathrm{lv}}=$ the volume of the left ventricle.

$V_{\mathrm{LV}}<b_{\mathrm{LV}}, a_{\mathrm{LV}}$ must be negative. This is consistent with the elastance ( $=1 /$ compliance) of the ventricle:

$$
d p_{6} / d V_{\mathrm{LV}}=2 a_{\mathrm{LV}}\left(V_{\mathrm{LV}}-b_{\mathrm{LV}}\right)(2)
$$

which is then positive over the range of the sketch. If the change in sign of $a_{\mathrm{LV}}$ is ignored, the broken part of the sketch changes to its mirror image, $p_{6}$ is always positive, while the elastance turns negative for $V_{\mathrm{LV}}<b_{\mathrm{LV}}$, all unrealistic features.

In the original computer experiments for Figs. 9 and 10 , ventricular volumes were sometimes found to be negative. Other investigators mentioned, though did not publish, similar observations for several years. Since negative ventricular volume is a physical impossibility, its origin was sought.

Figure 1(b) suggests the solution immediately: the discharge (outflow) from $\mathrm{C}_{9}$, the ventricular compliance, can continue beyond the empty state and the computer will designate such volume to be negative. The artifact of negative volume creation can be avoided by allowing the resistors $R_{\mathrm{lv}}$ to go to infinity as ventricular volume approaches zero, which is their sole function. For positive ventricular volumes $R_{\mathrm{lv}}$ values are negligibly small.
Figure 1(a), the model in fluid mechanical symbols, is not sensitive to this flaw, for the simple reason that flattening of the left ventricle eliminates communication between the ventricle and the venous and the arterial sides. $R_{\mathrm{lv}}$ 's are not required, though they are drawn is to show the need for them, and their location, in Fig. 1(b) where the venous and arterial parts of the model continue to communicate.

In mathematical terms, while including external pressure $p_{\mathrm{e}}(t)$, the ventricular pressure-volume relation reads:

$$
p_{6}(t)-p_{\mathrm{e}}(t)=a_{\mathrm{LV}}\left(V_{\mathrm{LV}}(t)-b_{\mathrm{LV}}\right)^{2}(3)
$$

for an asystolic ventricle $\left(F_{\mathrm{LV}}=0\right)$. If $p_{\mathrm{e}}(t)>p_{6}(t)$, the left hand side of the equation becomes negative, hence $a_{\mathrm{LV}}$ must be negative, which it is in the range where $V_{\mathrm{LV}}<$ $b_{\mathrm{LV}}$. Solving for $V_{\mathrm{LV}}$ under these conditions yields

$$
V_{\mathrm{LV}}=b_{\mathrm{LV}}-\left[\left(p_{\mathrm{e}}-p_{6}\right) /-a_{\mathrm{LV}}\right]^{1 / 2}(4)
$$

or $V_{\mathrm{LV}}$ will become negative when

$$
p_{\mathrm{e}}(t)-p_{6}(t)>-a_{\mathrm{LV}} b_{\mathrm{LV}}^{2}(5)
$$

which is a small positive pressure (Appendix 2). 


\section{CONCLUSION}

The primary conclusion is that the model ventricle performs physiologically in terms of flow, ejection curves and pressures. Under asystolic conditions, the model demonstrates potential for the cardiac pump mechanism are proposed by Kouwenhoven et al. The study also demonstrates that it allows further insights into the actual source of flow under incompetent valve conditions, both for a contracting heart and a heart under CPR conditions. The absence of contraction can, in principle, be replaced by external compression, provided the valves are competent (Fig. 8), increasing flow from 17 to $39 \mathrm{~mL} / \mathrm{s}$ with increasing $p_{\mathrm{e}}(t)$. If the valves are not competent the $8 \mathrm{~mL} / \mathrm{s}$ output is due to venous filling pressure and insensitive to external compression (Fig. 10). Impedance-defined flow demonstrates that sloshing, on the venous side, becomes dominant, negating effective movement.

\section{APPENDIX 1}

$$
\begin{aligned}
& Q_{\mathrm{H} 12}(t)= Q_{\mathrm{H} 13}(t) \\
& p_{\mathrm{ven}}-p_{5}^{*}(t)=\left(R_{\mathrm{LV}}+R_{\mathrm{lv}}\right) Q_{H 12}(t) \\
& p_{5}^{*}(t)=\left\{\begin{array}{c}
p_{6}(t) \text { if the mitral value is open } \\
p_{\mathrm{ven}} \text { if the mitral value is shut }
\end{array}\right. \\
& Q_{\mathrm{H} 13}(t)-Q_{\mathrm{H} 14}(t)=Q_{\mathrm{V} 9}(t) \\
& Q_{\mathrm{H} 14}(t)=Q_{\mathrm{H} 15}(t) \\
& p_{7}(t)=\left\{\begin{array}{l}
p_{6}(t) \text { if the aortic value is open } \\
p_{p}(t) \text { if the aortic value is shut }
\end{array}\right. \\
& p_{7}(t)-p_{p}(t)=\left(Z_{\mathrm{os}}+R_{\mathrm{lv}}\right) Q_{\mathrm{H} 15}(t) \\
& Q_{\mathrm{H} 15}(t)-Q_{1}(t)=Q_{\mathrm{V} 10}(t) \\
& Q_{V 10}=C_{10} \frac{\mathrm{d}}{\mathrm{d} t} p_{p}(t) \\
& V_{\mathrm{LV}}(t)= V_{\mathrm{LV}}(0)+\int_{0}^{t} Q_{\mathrm{V} 9}(t) \mathrm{d} t \\
& p_{6}(t)-p_{e}(t)= a_{\mathrm{LV}}\left(V_{\mathrm{LV}}-b_{\mathrm{LV}}\right)^{2}+\left(c_{\mathrm{LV}} V_{\mathrm{LV}}(t)\right. \\
&\left.-d_{\mathrm{LV}}\right) F_{\mathrm{LV}}(t)
\end{aligned}
$$

with

$$
\begin{aligned}
F_{\mathrm{LV}}(t)= & f_{\mathrm{LV}}(t)-k_{1} Q_{\mathrm{H} 15}(t) \\
& +k_{2}\left(Q_{H 15}\left(t-\tau_{\mathrm{LV}}(t)\right)^{2}\right) \\
\tau_{\mathrm{LV}}(t)= & \kappa_{\mathrm{LV}} t
\end{aligned}
$$

$$
\text { stroke volume }=\int_{0}^{t_{h}} Q_{\mathrm{H} 15}(t) \mathrm{d} t
$$

antegrade stroke volume $=\int_{0}^{t_{h}} \operatorname{pos} Q_{\mathrm{H} 15}(t) \mathrm{d} t$

retrograde stroke volume $=\int_{0}^{t_{h}}$ neg $Q_{\mathrm{H} 13}(t) \mathrm{d} t$

\section{APPENDIX 2}

$$
\begin{aligned}
& R_{\mathrm{LV}}=7.0 \times 10^{-3} \mathrm{mmHg} \mathrm{s} / \mathrm{mL} \\
& a_{\mathrm{LV}}=7.0 \times 10^{-4} \mathrm{mmHg} / \mathrm{mL}^{2} \\
& b_{\mathrm{LV}}=5.0 \mathrm{~mL} \\
& c_{\mathrm{LV}}=1.6 \mathrm{mmHg} / \mathrm{mL} \\
& d_{\mathrm{LV}}=1.0 \mathrm{mmHg} \\
& k_{1}=4.0 \times 10^{-4} \mathrm{~s} / \mathrm{mL} \\
& k_{2}=1.5 \times 10^{-6} \mathrm{~s}^{2} / \mathrm{mL}^{2} \\
& \kappa_{\mathrm{LV}}=0.45 \\
& Z_{\mathrm{os}}=8.0 \times 10^{-2} \mathrm{mmHg} \mathrm{s} / \mathrm{mL} \\
& C_{10}=2.75 \mathrm{~mL} / \mathrm{mmHg} \\
& t_{h}=1.0 \mathrm{~s} \\
& R_{\mathrm{lv}}=\left\{\begin{array}{lc}
10^{-2} V_{\mathrm{LV}}^{2} \mathrm{mmHg} \mathrm{s} / \mathrm{mL} & \begin{array}{c}
\text { until ventricle can refill } \\
\text { (volume driven) } \\
\text { until volume reaches a } \\
\text { maximum (pressure } \\
\text { driven) }
\end{array}
\end{array}\right.
\end{aligned}
$$

\section{REFERENCES}


Beyar R., Kishon Y, Dinnar U, and Neufeld NH. Cardiopulmonary resuscitation by intrathoracic pressure variation-In vivo studies and computer simulation. Angiology 35: 71-78, 1984.

Beyar R, Kishon Y, Kimmel E, Neufeld H, and Dinnar U. Intrathoracic and abdominal pressure variations as an efficient method of cardiopulmonary resuscitation: Studies in dogs compared with computer model results. Cardiovasc Res 19: 335-342, 1985.

Criley M, Blaufuss AH, and Kissel GL. Cough-induced cardiac compression: Self-administered form of cardiopulmonary resuscitation. JAMA 236(11): 1246-1250, 1976.

Danielsen M, Palladino JL, and Noordergraaf A. The left ventricular ejection effect. In Ottesen JT and Danielsen M, Eds., Mathematical Modeling in Medicine, Washington, DC, IOS Press, 2000.

De Pater L, and Van den Berg JW. An electrical analogue of the entire human circulatory system. Med Biol Eng Comput 2: 161-166, 1964.

Desmuhk HG, Weil MH, Rachow EC, Trevino R, and Bisera J. Echocardiographis observations durng cardiopulmonary resuscitation: A preliminary report. Crit Care Med 13(11): 904-906, 1985.

Halperin HR, Tsitlik JE, Beyar R, Chandra N, and Geurci AD. Intrathoracic pressure fluctuations move blood during CPR: Comparison of hemodynamic data with predictions from a mathematical model. Ann Biomed Eng 15: 385-403, 1987.

Harvey G. Exercitatio Anatomica, De Motu Cordis et Sanguinis in Animalibus. Frankford, 1628.

Karreman G, and Weygandt CN. Theoretical control aspects of the circulation. In Baan J, Noordergraaf A, and Raines J, Eds., Cardiovascular System Dynamics, Cambridge MA, MIT Press, 1978.

Klouche K, Weil MH, Sun S, Provoas HP, Kamohara T, and Bisera J. Evolution of the stone heart after prolonged cardiac arrest. Chest 122: 1006-1011, 2002.

Kouwenhoven WB, Jude JR, and Knickerbocker GG. Closed chest cardiac massage. JAMA 173: 1064-1067, 1960.

Liebau G. Über ein Ventilloses Pumpprinzip. Naturwissenschaften 41: 327-328, 1954.

Maier GW, Newton JR, Wolfe JA, Tyson GS, Olsen CO, Glower DD, Spratt JA, Davis JW, Feneley MP, and Rankin JS. The influence of manual chest compression rate on hemodynamic support dur- ing cardiac arrest: High impulse cardiopulmonary resuscitation. Circulation 74(IV): 51-59, 1986.

Moser M, Huang JW, Schwarz, Kenner T, and Noordergraaf A. Impedance-defined flow. Generalization of William Harvey's concept of the circulation-370 years later. Int J Cardiovasc Med Sci 1: 205-211, 1998.

Noordergraaf A. Blood in Motion. New York, Springer-Verlag, 2006 (in press).

Noordergraaf GJ, Ottesen JT, Kortsmit WJPM, Schilders WHA, Scheffer GJ, and Noordergraaf A. The Donders Model in Physiology, 2006 (in press).

Noordergraaf GJ, van Tilborg GFAJB, Schoonen JAP, Ottesen JT, and Noordergraaf A. Thoracic CT-scans and cardiovascular models: the effect of external force in CPR. Int J Cardiovasc Med Sci 5(1): 2005 (in press).

Ornato JP, Levine RL, Young DS, Racht EM, Garnett AR, and Gonzalez ER. The effect of applied chest compression force on systemic arterial pressure and end-tidal carbon dioxide concentration during CPR in human beings. Ann Emerg Med 18: 732-737, 1989.

Palladino JL, Ribeiro LC, and Noordergraaf A. Human circulatory system model based on Frank's mechanism. In Ottesen JT and Danielsen M, Eds., Mathematical Modelling in Medicine. Washington, DC, IOS Press, 2000.

Tomaszewski CA, and Meador SA. Theoretical effects of fluid infusions during cardiopulmonary resuscitation as demonstrated in a computer model of the circulation. Resuscitation 15(2): 97-112, 1987.

Weber EH. Über die Anwendung der Wellenlehre auf die Lehre vom Kreislaufe des Blutes und ins besondere auf die Pulslehre. Ber Verh Kgl Sächs Ges Wiss, Math Phys Kl, 1850.

Weiser FM, Adler LN, and Kuhn LA. Hemodynamic effects of closed and open cardiac resuscitation in normal dogs and those with acute myocardial infarction. Am J Cardiol 10: 555-561, 1962.

Westerhof N and Noordergraaf A. Reduced models of systemic arteries. Proceedings of the 8th Internatonal Conference on Medical Engineering, Chicago IL, Session 6-2, 1969.

Wolfram S. The Mathematica Book, 5th ed. Cambridge University Press, Cambridge, UK, 2003. 